\title{
Superamphiphobic Surfaces Prepared by Coating Multi-functional Nanofluids
}

\author{
Pouriya Esmaeilzadeh ${ }^{\dagger}$, Mohammad Taghi Sadeghi1 ${ }^{\dagger *}$, Alireza Bahramian ${ }^{\star *}$, Zahra \\ Fakhroueian ${ }^{\ddagger}$ and Ali Zarbakhsh ${ }^{\S_{*}}$
}

${ }^{\dagger}$ Chemical Engineering collage, Iran University of Science and Technology (IUST), Narmak, Tehran 16765-163, Iran

${ }^{\ddagger}$ Institute of Petroleum Engineering, University of Tehran, Tehran 11155-4563, Iran

${ }^{\S}$ School of Biological and Chemical Sciences, Queen Mary, University of London, Joseph

Priestley Building, Mile End Road, London E1 4NS, United Kingdom

\begin{abstract}
Construction of surfaces with the capability of repelling both water and oil is a challenging issue. We report the superamphiphobic properties of mineral surfaces coated with nanofluids based on synthesized Co-doped and Ce-doped Barium Strontium Titanate (CoBST and CeBST) nanoparticles and fluorochemicals of trichloro $(1 \mathrm{H}, 1 \mathrm{H}, 2 \mathrm{H}, 2 \mathrm{H}$-perfluorooctyl)silane (PFOS) and polytetrafluoroethylene (PTFE). Coating surfaces with these nanofluids provides both oil (with surface tensions as low as $23 \mathrm{mN} / \mathrm{m}$ ) and water repellency. Liquids with high surface tension (such as water and ethylene glycol) roll off the coated surface without tilting. A water drop released from $8 \mathrm{~mm}$ above the coated surface undergoes first a lateral displacement from its trajectory and shape deformation, striking the surface after $23 \mathrm{~ms}$, bouncing and rolling off freely. These multifunctional coating nanofluids impart properties of self-cleaning. Applications include coating surfaces where cleanliness is paramount such as in hospitals and domestic environments as well as the maintenance of building facades and protection of public monuments from weathering. These superamphiphobic doped nanofluids have thermal stability up to $180{ }^{\circ} \mathrm{C}$; novel industrial applications include within fracking and the elimination of condensate blockage in gas reservoirs.
\end{abstract}

\section{KEYWORDS}

Superamphiphobicity, Barium strontium titanate (BST), Self-cleaning, Nanofluid, Stability, Carbonate rock 


\section{Introduction}

In recent years, the fabrication of artificial superhydrophobic surfaces with water contact angles $>150^{\circ}$ and an effortless rolling-off of water (sliding angle $<5^{\circ}$ ) have attracted extensive attention because of their numerous applications, both industrial and domestic. ${ }^{1-6}$ These are inspired by the water repellence and self-cleaning properties of naturally occurring surfaces such as lotus leaves, butterfly wings and red rose petals amongst others. ${ }^{6-11}$ It is well known that the wettability of solid substrates depends on two key surface features: surface chemical composition and surface topography. ${ }^{6,10-13}$ Hence, to obtain superhydrophobic and superoleophobic (i.e. superamphiphobic) surfaces, a combination of surface roughness formation (topography) and lowering the surface energy are required.

Most biological superhydrophobic surfaces are generally extremely oleophilic and oils tend to spread on their surfaces. ${ }^{14}$ Many researchers have made contributions toward improving the amphiphobicity of various substrates such as glass, ${ }^{15-17}$ titanium foil, ${ }^{18,19}$ wood, ${ }^{20}$ stainless steel, 21,22 etc. $^{23,24}$ The main approach has been to lower the surface free energy by introducing fluorine-containing modifiers onto surfaces, resulting in the formation of a macro- or nanoscaled textured morphology.

Controlling the wettability of porous substrates such as rocks and stones is an important topic because of spontaneous imbibition of different liquids into porous media. This has many applications, for example, the protection of cultural heritage buildings from natural weathering. In order to control the weathering process, the application of water-repellent coatings onto the stone surface is normally used. ${ }^{25}$ Modifying the wettability of porous substrates from liquid wetting (oil or water) to gas-wetting (amphiphobic state) also has important industrial applications such as those in the gas reservoir engineering field. Mitigating the condensate blockage or condensate banking is an important challenge for engineers in order to increase gas well productivity.$^{26}$ Many gas wells in gas condensate reservoirs suffer a significant loss in productivity because of the accumulation of liquids (gas condensate and/or water) near the wellbore region. ${ }^{27}$ This blockage occurs because of a strong liquid wetting of the reservoir rock. One method to alleviate the blockage and to improve gas recovery is by chemical means. Li and Firoozabadi were the first to report the application of fluorochemical polymers to alter the liquidwet sandstone and chalk surface to achieve intermediate gas-wetness. ${ }^{28}$ Several researchers have 
tried to enhance the amphiphobicity of reservoir rocks by using various fluorochemical surfactants/polymers. ${ }^{29-34}$ However altering the wettability of reservoir rock, which is also compounded by pore composition geometry, size and overall roughness, to attain the allimportant superamphiphobic state, has yet to be fully achieved.

In this paper we report wetting properties of nanofluids formed by the synthesized Co- or Cedoped BST nanoparticles in combination with the low surface energy of trichloro $(1 \mathrm{H}, 1 \mathrm{H}, 2 \mathrm{H}, 2 \mathrm{H}-$ perfluorooctyl)silane (PFOS) and polytetrafluoroethylene (PTFE). We demonstrate that these nanofluids result in a significant improvement in the superamphiphobicity of surfaces. The superamphiphobicity and self-cleaning properties of cerium doped and cobalt doped barium strontium titanate nanofluids, which can be applied to change the wettability of a carbonate rock, will be discussed as one possible application. Barium Strontium Titanate nanofluid (BST) is a nano-sized perovskite-type metal oxide, known for its excellent ferroelectric, dielectric, thermal stability, piezoelectric and pyroelectric properties, and its potential applications in a variety of areas. ${ }^{35-37} \mathrm{Ba}_{0.5} \mathrm{Sr}_{0.5} \mathrm{TiO}_{3}$ (BST) were synthesized using a wet-chemical co-precipitation method through hydrothermal processing. The BST with specific cubic structures was then used as a nanocomposite substrate, doped by transition metal oxide of cobalt or lanthanide metal oxide of cerium, as surface promoters. These systems are fully characterized using a range of techniques. Static and dynamic contact angle experiments were used to measure the wettability of nanofluid modified rock substrates. The surface morphologies of these modified rock substrates were characterized by the use of EDX and SEM images.

\section{Experimental section}

\section{Chemicals}

Barium chloride dihydrate $\left(\mathrm{BaCl}_{2} \cdot 2 \mathrm{H}_{2} \mathrm{O}, 99 \%\right)$, strontium chloride dihydrate $\left(\mathrm{SrCl}_{2} .2 \mathrm{H}_{2} \mathrm{O}\right.$, 99\%) and tetraethyl orthotitanate (TEOT, $\left.\mathrm{Ti}\left(\mathrm{OC}_{2} \mathrm{H}_{5}\right)_{4},>99 \%\right)$ were purchased from Merck Company as the precursors for synthesizing BST nanoparticles. Cerium(III) nitrate hexahydrate $\left(\mathrm{Ce}\left(\mathrm{NO}_{3}\right)_{3} \cdot 6 \mathrm{H}_{2} \mathrm{O},>98.5 \%\right)$ and cobalt(II) nitrate hexahydrate $\left(\mathrm{Co}\left(\mathrm{NO}_{3}\right)_{2} \cdot 6 \mathrm{H}_{2} \mathrm{O}, \geq 99 \%\right)$ were received from Merck and used for doping. Ethylene glycol $\left(\mathrm{C}_{2} \mathrm{H}_{6} \mathrm{O}_{2}\right.$, Merck), propylene glycol $\left(\mathrm{C}_{3} \mathrm{H}_{8} \mathrm{O}_{2}\right.$, Merck), ethanol $\left(\mathrm{C}_{2} \mathrm{H}_{5} \mathrm{OH}\right.$, Merck), oxalic acid $\left(\mathrm{C}_{2} \mathrm{H}_{2} \mathrm{O}_{4}\right.$, Merck), glacial acetic acid $\left(\mathrm{C}_{2} \mathrm{H}_{4} \mathrm{O}_{4}\right.$, Merck) and polyethylene glycol ( $\mathrm{Mw}=1500$, Merck) were employed as other 
components during the synthesizing process of nanoparticles. Trichloro $(1 \mathrm{H}, 1 \mathrm{H}, 2 \mathrm{H}, 2 \mathrm{H}-$ perfluorooctyl)silane (PFOS, 97\%) and polytetrafluoroethylene (PTFE) were obtained from Sigma-Aldrich and used as received. Deionized water (Zolal Teb Co.), Lauryl alcohol $\left(\mathrm{C}_{12} \mathrm{H}_{26} \mathrm{O}\right.$, Merck), hexadecane $\left(\mathrm{C}_{16} \mathrm{H}_{34}\right.$, Merck), n-decane $\left(\mathrm{C}_{10} \mathrm{H}_{22}\right.$, Merck, $\left.>99 \%\right)$ and 2-butanol $\left(\mathrm{C}_{4} \mathrm{H}_{10} \mathrm{O}\right.$, Merck) were used as liquid phases in contact angle experiments.

\section{Synthesis of hydrophobic perovskite Co- and Ce-doped BST nanoparticles}

The precursor solutions for $\mathrm{Ba}_{0.5} \mathrm{Sr}_{0.5} \mathrm{TiO}_{3}$ nano-sized perovskite oxide were prepared by the sol-gel method using high purity $\mathrm{BaCl}_{2} \cdot 2 \mathrm{H}_{2} \mathrm{O}, \mathrm{SrCl}_{2} \cdot 2 \mathrm{H}_{2} \mathrm{O}$ and TEOT as the starting materials. The solid-state barium chloride dihydrate and strontium chloride dihydrate were initially dissolved in glacial acetic acid and oxalic acid to obtain a $(\mathrm{Ba}, \mathrm{Sr})$ stock solution through tuning the $\mathrm{pH}$ at 4 . The titanium solution was prepared by dissolving TBOT in ethylene glycol and propylene glycol was then added to the $(\mathrm{Ba}, \mathrm{Sr})$ stock solution at $60-70{ }^{\circ} \mathrm{C}$ under vigorous magnetic stirring. After thorough mixing, a solution of water and alcohol was added to it and the mixture refluxed for 0.5 hours. Next, to obtain Co-doped BST nanoparticles, a wet-chemical coprecipitation method through hydrothermal processing was employed. For this purpose, $2.5 \mathrm{~g}$ of $\mathrm{Co}\left(\mathrm{NO}_{3}\right)_{2} .6 \mathrm{H}_{2} \mathrm{O}$ and polyethylene glycol 1500 were added to resultant $\mathrm{Ba}_{0.5} \mathrm{Sr}_{0.5} \mathrm{TiO}_{3}$ sol as an effective promotor and surface co-modifier, respectively, and the $\mathrm{pH}$ of mixture was adjusted to 4-5. Then, the pink mixture was refluxed for 72 hours. The final product was filtered, washed by water and alcohol solution, dried hydrothermally in an oven at $100{ }^{\circ} \mathrm{C}$ and finally calcined at 850 ${ }^{\circ} \mathrm{C}$ for 6-8 hours in a muffle furnace. For synthesizing Ce-doped BST, nanoparticles $\mathrm{Ce}\left(\mathrm{NO}_{3}\right)_{3} \cdot 6 \mathrm{H}_{2} \mathrm{O}$ was added to resultant $\mathrm{Ba}_{0.5} \mathrm{Sr}_{0.5} \mathrm{TiO}_{3}$ sol as an effective promotor and the $\mathrm{pH}$ was adjusted to 3 resulting in an orange mixture. The same procedure as above was used for Codoped BST nanoparticles and then employed to obtain the final Ce-doped BST nanoparticles products.

\section{CoBST and CeBST nanofluids}

The nanoparticle-to-fluorochemicals mass fraction ratio was optimized for the nanofluids formulations to gain contact angles of interest. The ratio was varied between 0 and 0.6. A procedure to produce both Co- and Ce-doped BST nanofluids with an optimum nanoparticle-tofluorochemicals ratio of 0.17 (to be discussed later) is as follows: $0.02 \mathrm{~g}$ of their corresponding 
synthesized nanoparticles were dispersed into $10 \mathrm{~mL}$ of ethanol, first. Then, a fluoro-containing mixture consisting of $0.02 \mathrm{~g}$ PTFE and $10 \mathrm{~mL}$ of an alcoholic based emulsion containing PFOS were added to the solution. The concentration of fluorochemicals used in the nanofluids is an optimal proportion based on economic viewpoints because no apparent better performance of liquid repellency was seen with higher concentrations. The solution was sonicated for 40 minutes in an ultrasonic bath, followed by 30 minutes agitation on a heater stirrer at $50^{\circ} \mathrm{C}^{38,39} \mathrm{~A}$ full description of the treatment process of rock plates substrates with the nanofluids and the technical details of the instrumentations used for the characterization of the samples discussed below are given in the Supporting Information (S1 and S2).

\section{Results and discussion}

SEM images for the synthesized nanoparticles are shown in Fig. 1. It can be found that both CoBST and CeBST nanopowders have structures composed of faceted grains with a high degree of agglomeration constituted by numerous small particles with approximately spherical shape. ${ }^{40-}$ ${ }^{42}$ In addition, it can be seen that the morphology of CoBST also consists of nanotubes Fig 1(b). The agglomeration process is ascribed to particle growth during the applied calcination process $\left(850{ }^{\circ} \mathrm{C}\right.$ for $\left.6-8 \mathrm{~h}\right) .{ }^{40,42}$

TEM micrographs, Fig 2, show that the CoBST and CeBST powders are in the form of agglomerates and near-spherical particles in the dispersed solution. Fig. 2(b) also clearly illustrates the presence of nanotubes in combination with agglomerated grains and near-spherical particles. The images support the nanometric nature of CoBST and CeBST particles. Figs. 2(a) and 2(b) show the particle sizes for the CoBST to be about 7-30 nm with a distribution of 7-15 $\mathrm{nm}$ for spheres and grains and 22-35 nm for tubes. Figs. 2(c) and 2(d) also show that the particle sizes of CeBST are approximately 10-30 nm for spheres and agglomerated grains.

FTIR results (Fig. S1, see Supporting Information) peaks are observed at $\sim 3420-3430$ and $1605-1610 \mathrm{~cm}^{-1}$ corresponding to stretching and bending vibration modes of the $\mathrm{O}-\mathrm{H}$ group. ${ }^{43,44}$ The bands at $2923 \mathrm{~cm}^{-1}$ are related to the $\mathrm{C}-\mathrm{H}$ bending vibration. The peaks are also observed at $872 \mathrm{~cm}^{-1}$ corresponding to a Ti-O bond. The peaks $\sim 450-800 \mathrm{~cm}^{-1}$ are assigned to the formation of metal oxides (Ba-O, Sr-O, CO-O and $\mathrm{Ce}-\mathrm{O}){ }^{45,46}$ The XRD patterns for the CoBST and CeBST nanoparticles (Fig. S2, see Supporting Information) show strong diffraction peaks at $32^{\circ}$, 
$38^{\circ}, 46^{\circ}$ and $57^{\circ}$ and can be attributed to the (110), (111), (200) and (211) crystal planes. ${ }^{46,47}$ The peaks are compatible with JCPDS card number 39-1395, indicating a cubic structure for these perovskite nanoparticles. The UV-Vis absorption spectrum of CoBST and CeBST (Fig. S3, see Supporting Information) covering the wavelength, range from $190 \mathrm{~nm}$ to $800 \mathrm{~nm}$. These spectra show that the absorption edge is shifted to 193 and $226 \mathrm{~nm}$ (blue emission). ${ }^{46}$ This fact is indicative of a possible wide band gap energy, high surface area and large surface porosities in their functionalized surfaces. Furthermore, the UV-Vis results confirm the size of nanoparticles measured by TEM.
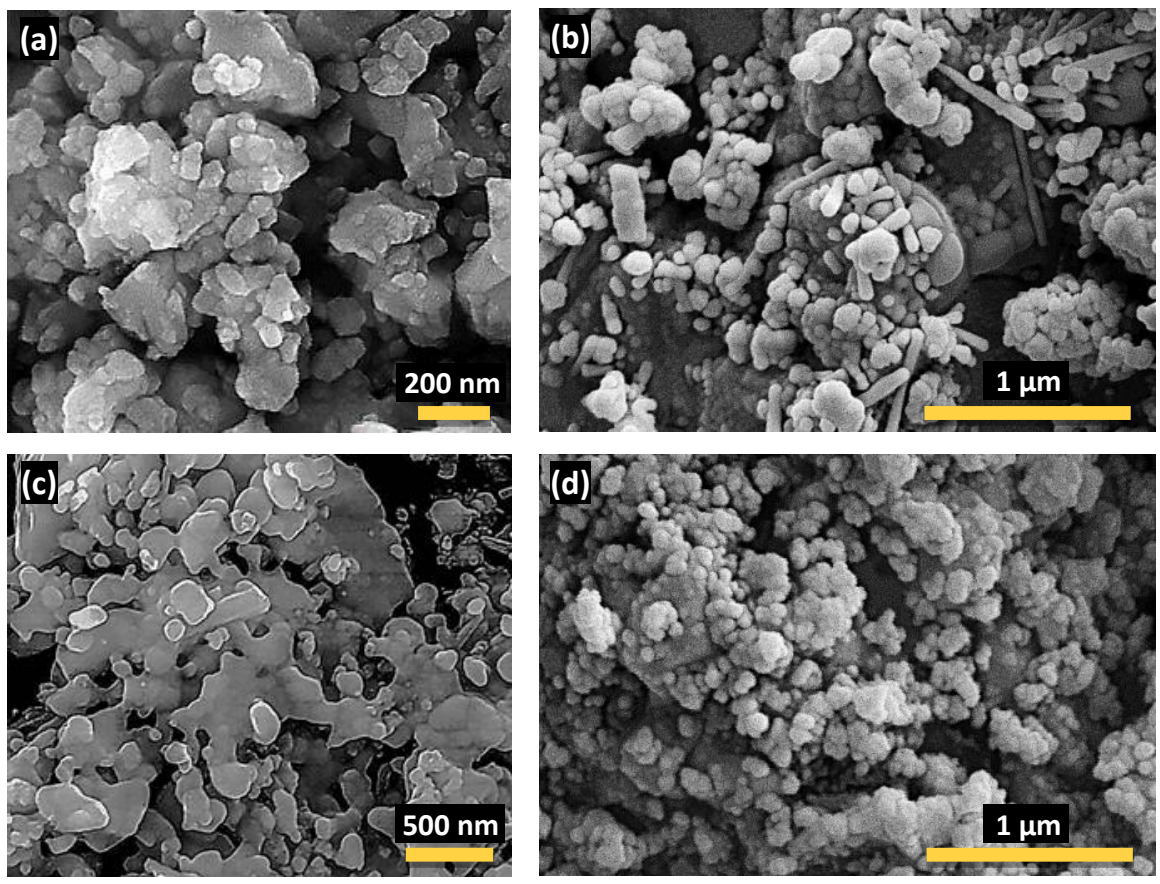

Fig. 1. SEM images of synthesized (a), (b) CoBST and (c), (d) CeBST nanopowders calcined at $850{ }^{\circ} \mathrm{C}$ for $6-8 \mathrm{~h}$. 

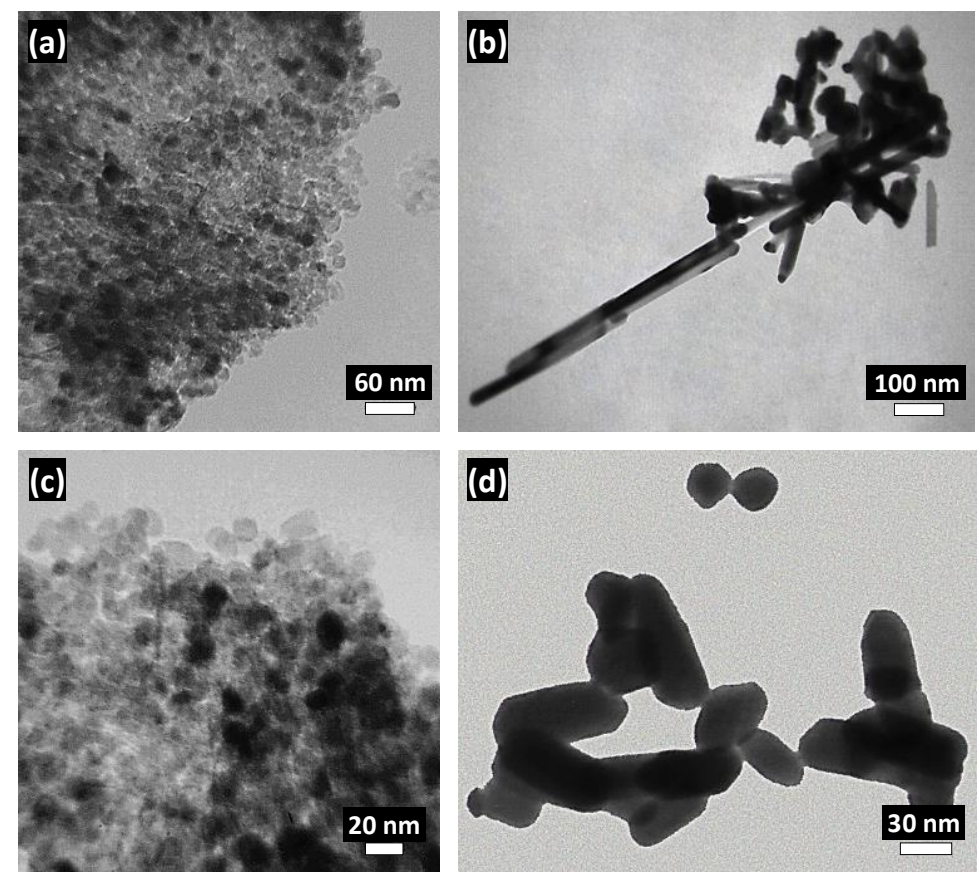

Fig. 2. TEM images of synthesized perovskite nanoparticles: (a), (b) CoBST and (c), (d) CeBST.

\section{Surface wettability}

Static contact angles of water and oil droplets on carbonate rock plates, before and after treatment with the doped nanofluids, are presented in Fig. 3. The static contact angle values correspond to the average taken from 3-5 measurements at different positions on each sample and are shown in Fig. 3. As it is evident from the figure, the untreated rock plates are strongly liquid-wet with the contact angle of $0^{\circ}$ for both water and n-decane (Fig. 3(a)). After coating the plates with CoBST nanofluid, the contact angle drastically increased to $162^{\circ}$ for water and to $145^{\circ}$ for n-decane (Fig. 3(b)). Higher contact angles for both oil and water were observed for the plates treated with CeBST nanofluid, Fig. 3(c). The treatment of rock plates with CeBST nanofluid resulted in water and $n$-decane static contact angles of $164^{\circ}$ and $152^{\circ}$ respectively. These measurements clearly show that CoBST and CeBST nanofluids treated plates resulted in much greater static contact angles than those reported for a chemically modified substrate using fluorinated polymers. ${ }^{48}$ The data reported here show successful modification of the wettability of a mineral surface from liquid-wetting to a superamphiphobic state achieved with perovskite-type nanofluids. 
(a) Untreated rock plates

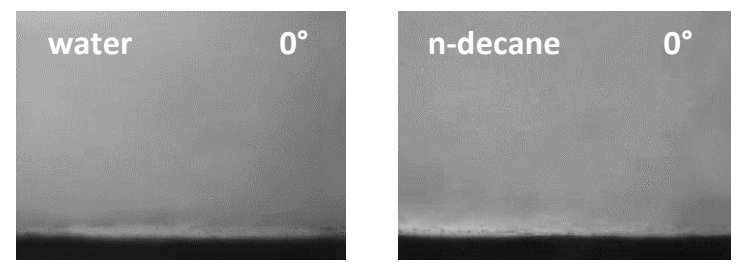

(b) After treatment with CoBST nanofluid

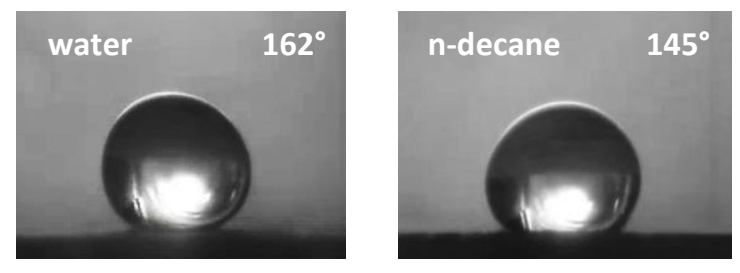

(c) After treatment with CeBST nanofluid

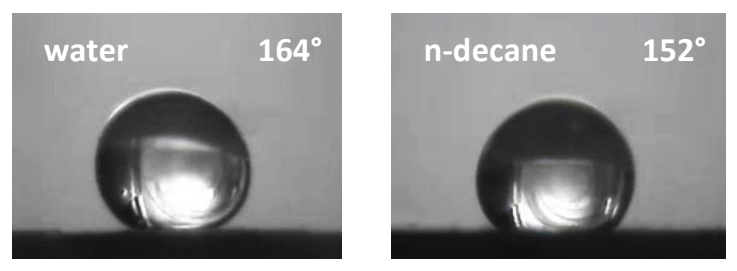

Fig. 3. Cross-sectional view of water and n-decane droplets on rock plates (a) before treatment and after treatment with (b) CoBST and (c) CeBST nanofluids, respectively.

Fig. 4 shows the time-dependent contact angle values for water and n-decane on surfaces of plates treated with CoBST and CeBST nanofluids. The ageing time is an important parameter for the practical application of these nanofluids to alter the wettability of mineral surfaces. The data show that for a full superamphiphobic state to be achieved, a minimum of 24 hours is required.

It is well-known that surface roughness combined with low surface energy of materials can influence the contact angle of liquid drops on solid surfaces and result in a non-wetting property. Hence the surface topography of the rock plate surfaces was examined using SEM. Fig. 5 shows the SEM images of the rock plates before and after treatment with the (CoBST and CeBST) nanofluids. The SEM images show the formation of sphere-like nanostructures of approximately 30-60 $\mathrm{nm}$ and 22-50 $\mathrm{nm}$ in diameter for the plates treated with CoBST and CeBST nanofluids, respectively. Moreover, the formation of nanotubes with an average size of 30-35 nm in diameter for CoBST coated plates can be distinctly recognized in Fig. 5(d). 

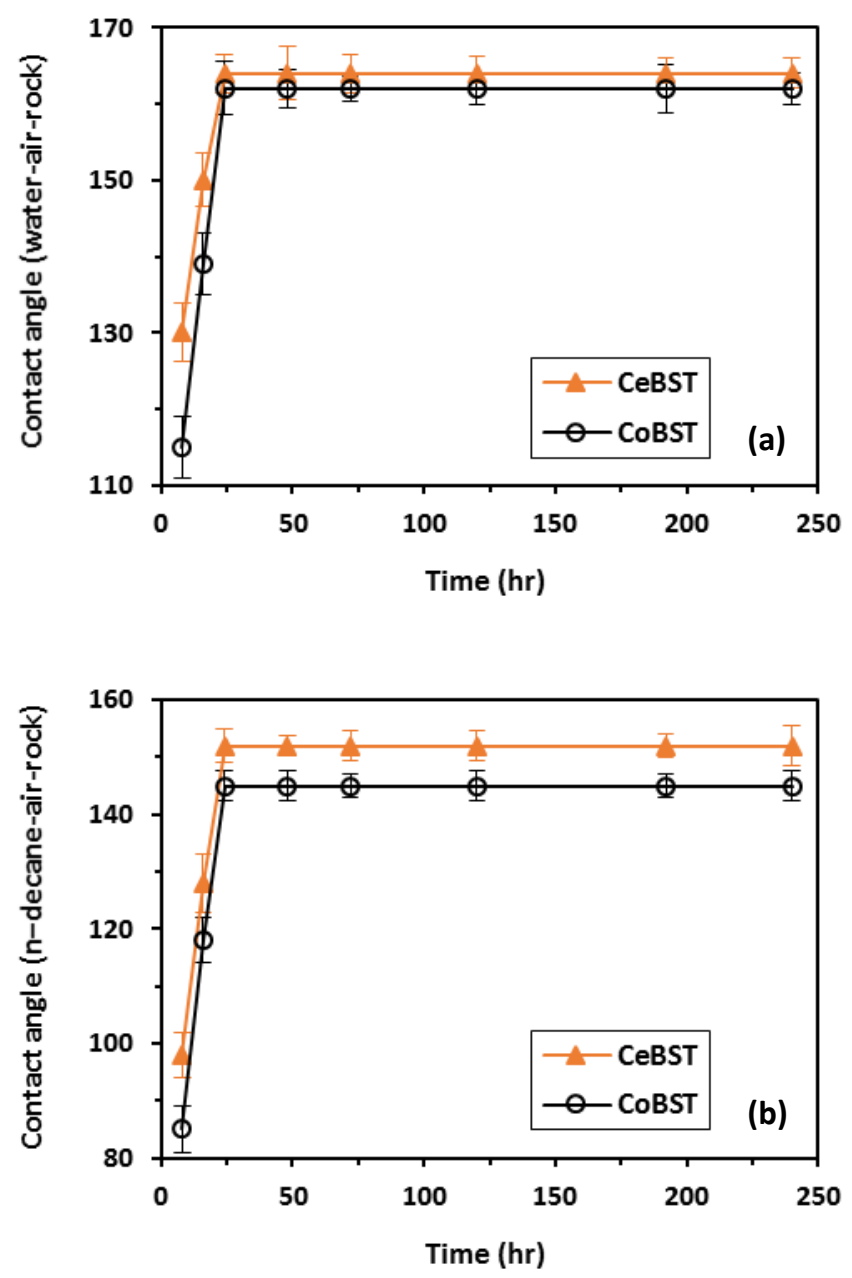

Fig. 4. Impact of ageing time on the wettability of rock plates treated with CoBST and CeBST nanofluids as measured by (a) water and (b) n-decane contact angles.

The formation of a nanostructured coating on the original microscale texture of the rock plates results in the formation of an hierarchical nano-submicron-scaled composite surface roughness. These roughened surfaces are then capable of trapping air between the surface cavities and the liquid layer, resulting in a suspension of liquid droplets on the roughened textured surface rendering the surface superamphiphobic.

This superamphiphobicity can be explained using the Cassie model. ${ }^{49}$ In the Cassie regime, a liquid droplet (spherical in shape) sits on top of roughened solid surface with an air packet trapped underneath. Accordingly, the model can be described as follows:

$\operatorname{Cos} \theta_{C B}=f_{1} \operatorname{Cos} \theta-f_{2}$ 
Where $\theta_{C B}$ and $\theta$ are the contact angle of a liquid drop on the rough and flat surface, respectively, and $f_{1}$ and $f_{2}\left(=1-f_{1}\right)$ are the area fraction of a droplet in contact with the solid and with air trapped in the asperities of the rough surface, respectively. Based on contact angle values measured for water and n-decane on the flat (rock surfaces before treatment) and the treated rock plates, the solid fraction in contact with liquid droplets $\left(f_{1}\right)$ can be estimated. For the plates treated with CoBST nanofluid the calculated $f_{l}$ values for water and n-decane were $2.4 \%$ and $9.0 \%$, respectively, and for the plates treated with CeBST nanofluid the $f_{1}$ values were calculated $1.9 \%$ and $5.9 \%$ for water and n-decane. To support the above calculations, we measured the water and oil contact angle on plates treated with CoBST and CeBST nanofluids in absence of organofluorinated chemicals including PTFE and PFOS mixtures. Contact angles of $100^{\circ}$ and $140^{\circ}$ in the absence of fluoro-containing materials were recorded for water on CoBST and CeBST treated surfaces, respectively. The contact angle of n-decane on both surfaces was $0^{\circ}$. These results demonstrate first, that the Co- and Ce-doped BST nanoparticles used in this work are originally hydrophobic. This feature was attained by physical and chemical modification of the nanoparticles' surfaces during the synthesis process. Second, it confirms that the CeBST nanoparticles are rougher than CoBST nanoparticles, resulting in a lower area fraction of water drop in contact with the plate. The calculated $f_{l}$ values of water for the plates treated with CoBST and CeBST solutions are $41.3 \%$ and $11.7 \%$, respectively. Such a lower water wetting fraction for the plate coated with CeBST nanoparticles results in a larger amount of air pocket trapping among the gaps of the rough surface and results in a higher contact angle of water. However, a comparison of these data with the results of water and n-decane contact angles on the plates treated with the nanofluids, indicates that beside the surface topography, the presence of fluoro-containing chemicals plays a very important role in repelling the n-decane droplets. This also results in an improvement of the water contact angle. It is noteworthy that the PTFE possesses a low surface free energy value of $18.5 \mathrm{mN} / \mathrm{m} .{ }^{50}$ Moreover, PFOS has a very low surface energy due to its high content of $-\mathrm{CF}_{3}$ and $-\mathrm{CF}_{2}$ functional groups. It has been reported that $-\mathrm{CF}_{3}$ terminated surfaces possess a low surface energy of $\sim 6 \mathrm{mN} / \mathrm{m}^{.}{ }^{50,51}$ 

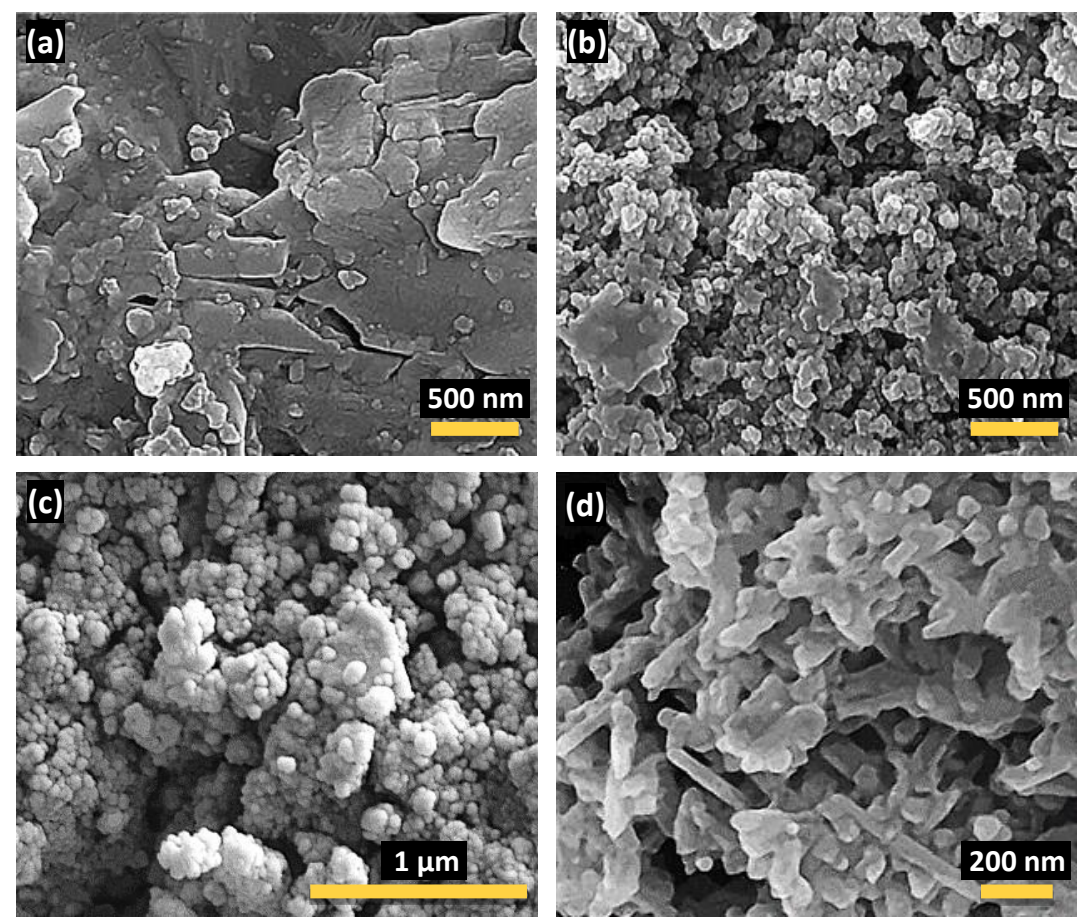

Fig. 5. SEM images of carbonate rocks (a) before treatment and after treatment with (b) CeBST and (c), (d) CoBST nanofluids, respectively.

The EDX analysis of the untreated and treated rock plates with CoBST and CeBST nanofluids (Fig. S4, see Supporting Information) provides evidence that the original carbonate rock, as expected, is mainly composed of Ca without the presence of elements within the nanoparticles and fluorochemicals. After treating the rock plate with the nanofluids, the constituent materials of CoBST and CeBST nanofluids, containing nanoparticle elements $\mathrm{Co}, \mathrm{Ce}, \mathrm{Ba}, \mathrm{Sr}$ and $\mathrm{Ti}$, and fluoro-containing elements F and Si, were identified on the surface (Figs. 5(b), 5(c) and 5(d)). The presence of these elements proves the adsorption of nanoparticles and fluorochemicals on the rock.

Static contact angle and contact angle hysteresis of water and oil measured on rock plates treated with CeBST nanofluids with various nanoparticle-to-fluorochemicals mass fraction ratios are shown in Fig. 6. A similar trend was also observed for CoBST nanofluids. As it is evident from this figure, the introduction of nanoparticles to the nanofluid formulation impressively facilitates an enhancement of water and n-decane repellencies. This proves that the nanoparticleto-fluorochemicals ratio plays a crucial role in affecting both water and oil repellencies. At a nanoparticle-to-fluorochemicals ratio of between 0.17 and 0.35 , the contact angle is higher than 
$160^{\circ}$ for water and is higher than $150^{\circ}$ for n-decane. The contact angle hysteresis was less than $10^{\circ}$ at a ratio of between 0.17 and 0.3 . It is believed that the addition of nanoparticles leads to formation of surface roughness conducive to air pocket formation. The superamphiphobicity of the coating is obtained as a result. However, excessive addition of nanoparticles cannot enhance the superamphiphobicity, and a nanoparticle-to-fluorochemicals ratio of 0.17 is optimum for attaining the best water and oil repellencies. A large amount of nanoparticles with fewer fluorochemicals results in the excess nanoparticles covering some surface cavities (moving towards smooth roughness properties), hence it only contributes a minor or negative influence in improving the water and oil repellency of the coating.

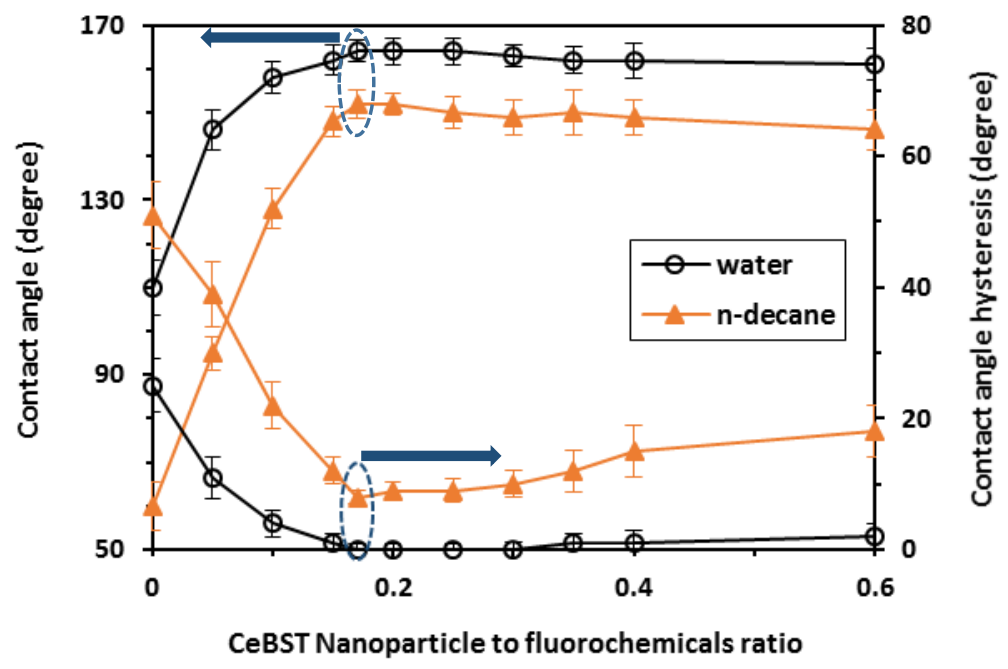

Fig. 6. Effect of nanoparticle-to-fluorochemicals mass fraction ratio on contact angle and contact angle hysteresis of water and n-decane, measured for the treated rock plates with CeBST nanofluids.

To evaluate further the water and oil repellency from the resulting coatings on the rock, the contact angle and contact angle hysteresis of eight liquids with different surface tensions, ranging from 23.4 to $73.2 \mathrm{mN} / \mathrm{m}$ were measured. The liquids are deionized water $(73.2 \mathrm{mN} / \mathrm{m})$, ethylene glycol $(48 \mathrm{mN} / \mathrm{m})$, lauryl alcohol $(32.2 \mathrm{mN} / \mathrm{m})$, hexadecane $(27.3 \mathrm{mN} / \mathrm{m})$, n-decane $(23.8$ $\mathrm{mN} / \mathrm{m})$, 2-butanol $(23.0 \mathrm{mN} / \mathrm{m})$ and ethanol $(22.0 \mathrm{mN} / \mathrm{m})$. The contact angles of the above mentioned liquids show a clear decrease with reduction of surface tension, while their contact angle hystereses increase with surface tension reduction (Table 1). 


\section{Table 1}

Contact angle (CA), contact angle hysteresis $(\mathrm{CAH})$ and surface fraction $\left(f_{l}\right)$ values of various liquids as a function of liquid surface tension

\begin{tabular}{lllllllll}
\hline Liquids & $\begin{array}{l}\text { Surface } \\
\text { Tension }\end{array}$ & \multicolumn{7}{c}{ CoBST } \\
\cline { 3 - 8 } & & CA & CAH & $f_{1}$ & CA & CAH & $f_{1}$ \\
\hline Water & 73.2 & $162 \pm 2$ & $0 \pm 1$ & 0.024 & $164 \pm 1$ & $0 \pm 1$ & 0.019 \\
Ethylene glycol & 48 & $160 \pm 3$ & $1 \pm 1$ & 0.030 & $163 \pm 2$ & $1 \pm 1$ & 0.022 \\
Lauryl alcohol & 32.2 & $154 \pm 2$ & $4 \pm 2$ & 0.051 & $159 \pm 2$ & $4 \pm 2$ & 0.033 \\
Hexadecane & 27.3 & $149 \pm 3$ & $6 \pm 3$ & 0.072 & $156 \pm 3$ & $5 \pm 3$ & 0.043 \\
N-decane & 23.8 & $145 \pm 2$ & $8 \pm 2$ & 0.090 & $152 \pm 3$ & $7 \pm 2$ & 0.059 \\
2-butanol & 23 & $143 \pm 3$ & $13 \pm 2$ & 0.100 & $151 \pm 3$ & $11 \pm 2$ & 0.063 \\
Ethanol & 22 & $140 \pm 2$ & $14 \pm 2$ & 0.117 & $148 \pm 2$ & $12 \pm 2$ & 0.076 \\
\hline
\end{tabular}

Comparing the surfaces treated with CoBST and CeBST nanofluids demonstrate that the latter nanofluid has a better superamphiphobicity properties than the former. Surface fraction $\left(f_{l}\right)$ values as a function of surface tension (Table 1) confirm that the solid fraction in contact with liquids with various surface tensions can be graded as: CoBST $>$ CeBST .

Fig. 7 shows the contact angles of 2-butanol and ethanol as low surface tension liquids on treated rock plates with CoBST and CeBST nanofluids. It was found that these liquid drops sit on the coatings and do not roll off the surface with no tilt of the rock substrate. This refers to their contact angle hysteresis which is not low enough that let the droplets roll off the surface without tilting. However, the liquid drops start to roll off the coating if the rock plate is tilted. The sliding angles of 2-butanol and ethanol are measured to be $15-18^{\circ}$.

To obtain the critical surface tension of treated rock surfaces with CoBST and CeBST nanofluids, the Zisman plot was constructed by plotting the cosine of the measured contact angles of a homologous series of liquids (n-alkanes) versus surface tension of the tested liquids (Fig. S5, see Supporting Information). According to the figure, any liquid whose surface tension equals or is less than 17.9 and $17.8 \mathrm{mN} / \mathrm{m}$ will make a zero contact angle and, accordingly, will completely spread on the surface of the rocks treated with CoBST and CeBST nanofluids. 
(a) After treatment with CoBST nanofluid

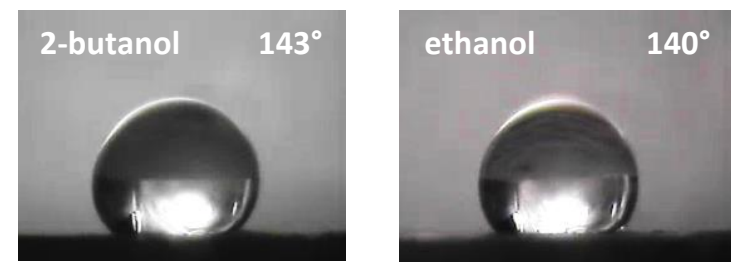

(b) After treatment with CeBST nanofluid

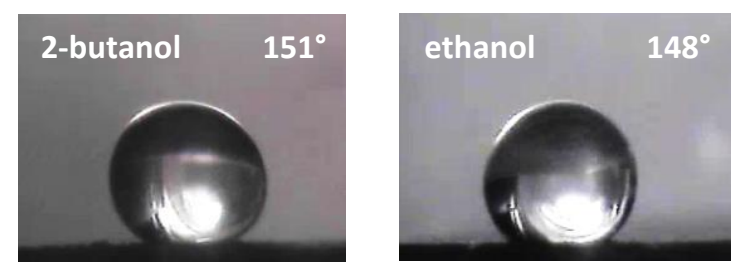

Fig. 7. Cross-sectional view of low surface tension liquids (2-butanol and ethanol) droplets on rock plates after treatment with (a) CoBST and (b) CeBST nanofluids.

\section{Self-cleaning properties of the surfaces treated with CoBST and CeBST nanofluids}

The $f_{l}$ value for water and ethylene glycol droplets are $2.4 \%$ and $3 \%$ on the plates treated with CoBST nanofluid and $1.9 \%$ and $2.2 \%$ on the plates treated with CeBST nanofluid. The very low wetting fraction of the rock with water and ethylene glycol (or more air pockets confined under the droplets) results in a short solid-liquid contact line that enhances the drop-rolling capability. For instance, Fig. 8(a) illustrates the self-cleaning property of CoBST nanoparticles coated rock. A jet of water was poured from an initial height of $8 \mathrm{~mm}$ above the surface of a rock plate treated with CoBST nanofluid using a syringe. As can be seen in this figure, different volumes of water roll-off easily on the rock surface with a sliding angle of $0^{\circ}$ for water. This means that the water drops start to roll-off on the surface with no tilt of the rock substrate. Fig. 8(b) also shows the motion of a $5 \mu \mathrm{l}$ water droplet falling from the same height $(8 \mathrm{~mm})$ on a rock surface treated with the CoBST nanofluid. As the image shows, the droplet experiences an elastic force as it approaches the surface of the nanostructures coated rock substrate. This results in lateral displacement of the droplet from the original release point by $\sim 11 \mathrm{~mm}$ and a shape deformation before the droplet finally strikes the surface after $23 \mathrm{mS}$. The kinetic energy of the droplet is then transformed into vibrational energy, resulting in the droplet bouncing twice before it undergoes descending oscillations and eventually the droplet rolls off freely on the surface. The trajectory of the droplet is shown schematically by a white dotted line. 
Moreover, it is known that for self-cleaning properties, a contact angle hysteresis less than $10^{\circ}$ is desired ${ }^{52,53}$ The value of the contact angle hysteresis for the CoBST nanotextured surface was measured as quasi-null for water. Such a minimum contact angle hysteresis, confirms the ability of water drops to roll-off freely on the surface of the rock with zero tilt without leaving a trace. Note that the same results were observed for ethylene glycol on treated plates with CoBST nanofluid and water and ethylene glycol on the plates aged in CeBST nanofluid. Also, as illustrated in Fig. 7, the contact angle hysteresis of the low surface tension liquids is mainly $<10^{\circ}$ for the coated plates with CoBST and CeBST. The results reflect that CoBST and CeBST nanotextures on surface of plates possess a good self-cleaning property for both water and oil.

It is noteworthy that low values of sliding angle and contact angle hysteresis indicate that a liquid has low adhesion to a solid and thus can roll-off easily. Therefore, studying the microscopic work of adhesion $\left(W_{a d}\right)$ can present useful information about the rolling behavior of a liquid on the surface of a solid. The work of adhesion on a rough surface can be estimated based on the Young-Dupre equation, ${ }^{3}$ which is expressed as follows, where $\gamma_{L}$ is the liquid surface tension:

$W_{a d}=f_{1} \gamma_{L}\left(1+\operatorname{Cos} \theta_{C B}\right)$

The calculated $W_{\text {ad }}$ values for water and ethylene glycol are $\sim 0.08 \mathrm{mN} / \mathrm{m}$ for the plates aged in CoBST nanofluid and $\sim 0.05 \mathrm{mN} / \mathrm{m}$ for the plates treated with CeBST nanofluid. The result confirms the minimum interaction of liquid/solid due to the high amount of air pockets, trapped through the pores of nano-submicron-scaled composite surface roughness, which leads to the liquid droplets on the solid surface freely rolling off. 

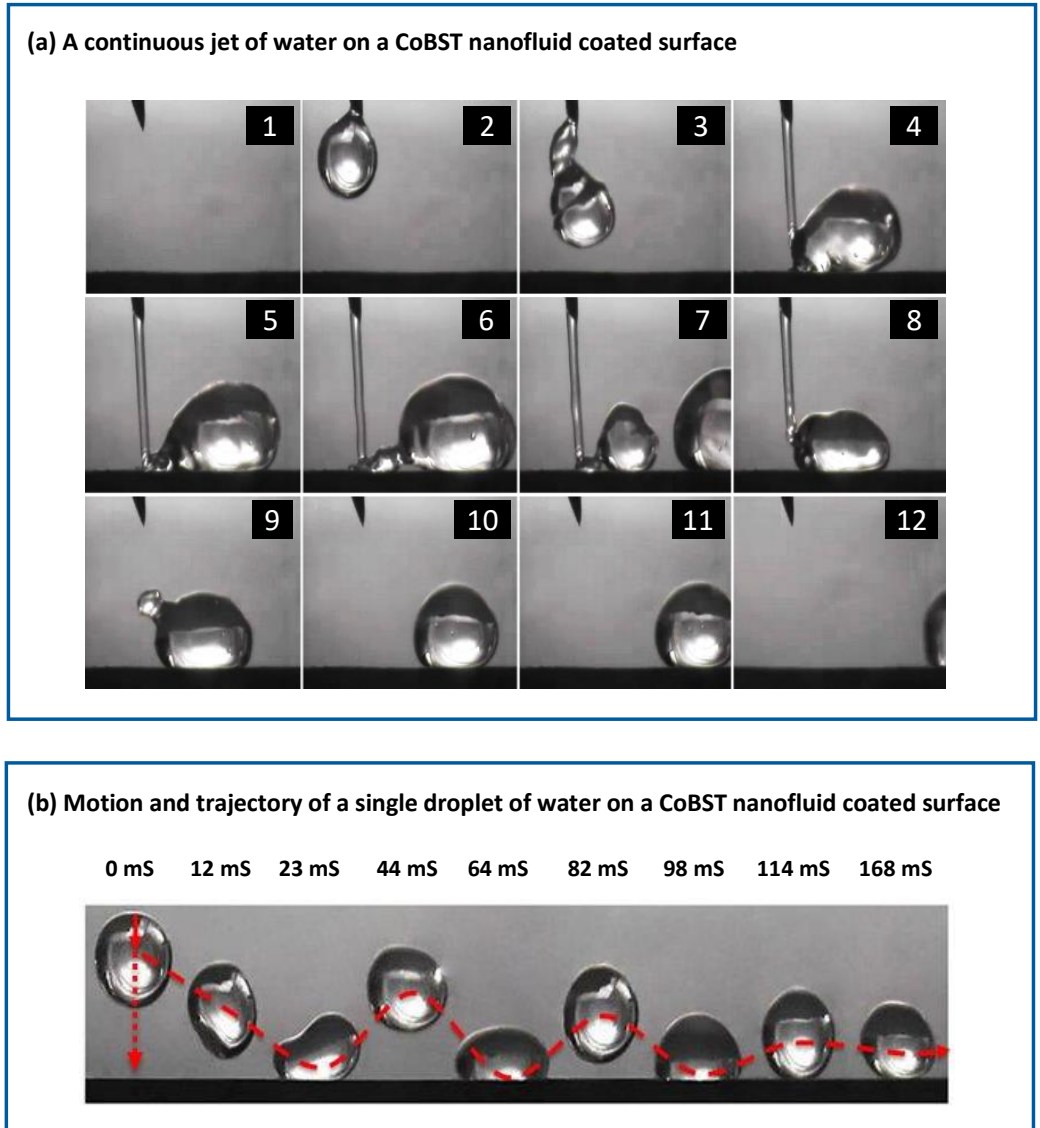

Fig. 8. (a) Time sequence images of a jet of water rolling-off freely on a rock surface treated with the CoBST nanofluid. (b) Motion and the trajectory (dotted line) of a $5 \mu 1$ water droplet released at a height of $8 \mathrm{~mm}$ at $0 \mathrm{mS}$ onto a rock surface treated with the CoBST nanofluid as a function of time.

\section{Durability, mechanical and thermal stability of superamphiphobic nanotextures}

The durability test of the superamphiphobic coatings were carried out in wet impregnation conditions for a long period. Thus, the treated plates with CoBST and CeBST nanofluids were fully submerged in water at $80{ }^{\circ} \mathrm{C}$ for 10 days. The repellency of the samples toward water and oil was measured every 48 hours. The plates were oven-dried at $80{ }^{\circ} \mathrm{C}$ for an hour prior to the contact angle measurement test. Fig. 9 shows the change in the water and n-decane contact angle of the treated rock plates with CoBST and CeBST nanofluids as a function of immersion time. A slight decline of contact angles indicates that the nanostructure coating on the treated plates shows a promising potential for having long-period durability. 
Moreover, the contact angle of water and n-decane were measured after the coated plates were left in air without special protection for a year. The contact angles of water and n-decane remained almost constant. It reflects that the treated plates possess a durable coating which suffers no change in super water and oil repellency by exposure to the air.
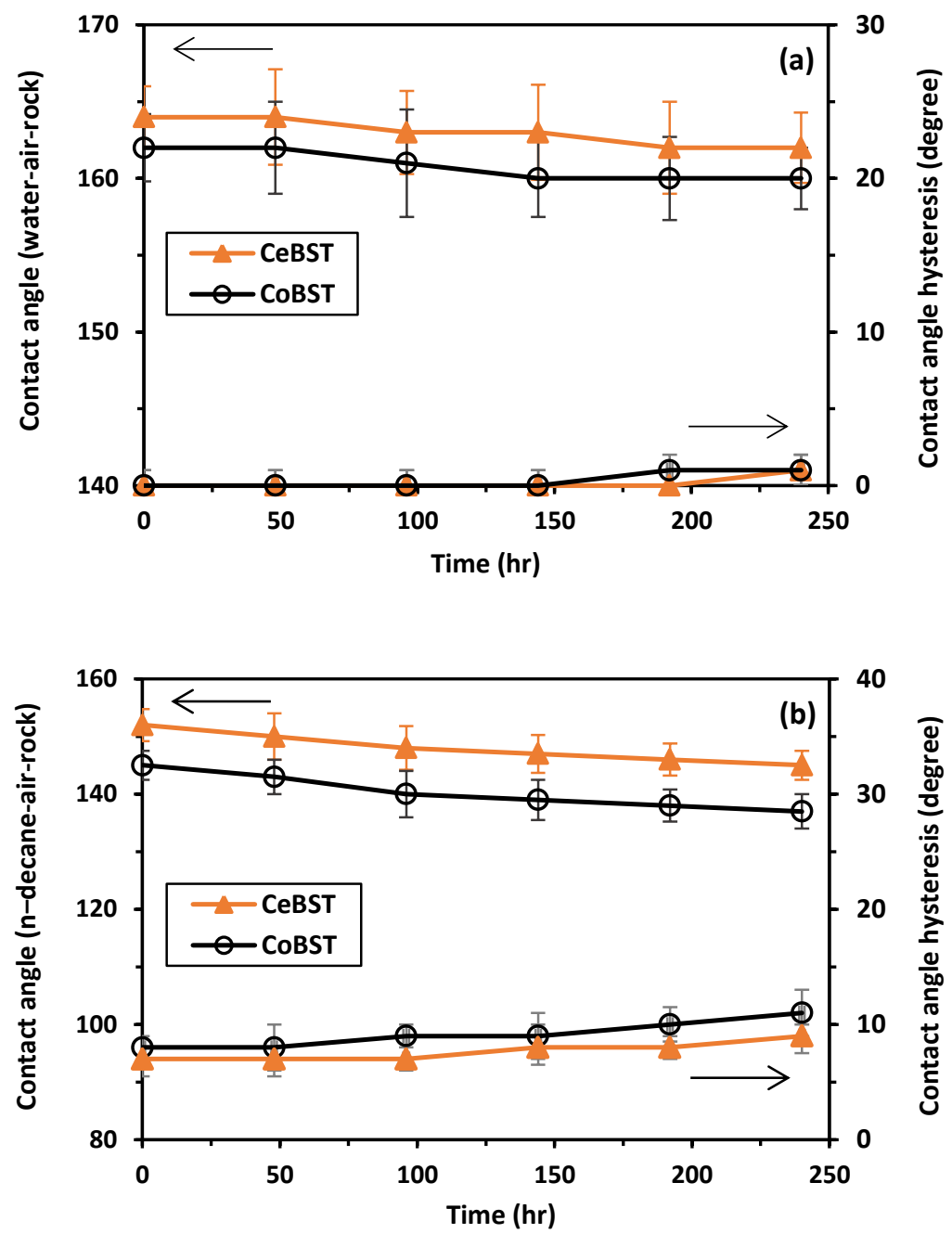

Fig. 9 variation of (a) water and (b) n-decane contact angles and contact angle hysteresis on the treated rock plates with CoBST and CeBST nanofluids as a function of water immersion period.

The mechanical stability of the coatings was first evaluated by finger pressing with a bare hand. ${ }^{54}$ If surface textures are fragile, the force exerted by touching will hurt them and makes the touched location decrease or even permanently lose its superamphiphobicity. Moreover, salts and oil contaminations could be induced by finger pressing to the surface, which is also a threat to 
the superamphiphobic stability. It was found that superamphiphobicity of the plates coated with CoBST and CeBST nanotextures remained unchanged after being pressed with a finger.

Next, in order to study the mechanical abrasion resistance of the coatings, an abrasion test was carried out. ${ }^{54,55}$ In this test, a 240 grit sandpaper with $20 \mathrm{~cm}$ length served as an abrasion surface and the superamphiphobic surfaces with a contact area of $3 \mathrm{~cm} \times 3 \mathrm{~cm}$ were moved back and forth on the sandpaper under $500 \mathrm{~g}$ of force (pressure of $5.4 \mathrm{KPa}$ ) for 20 cycles (Fig. 10(a)). The changes in contact angle and contact angle hysteresis versus abrasion cycles for water and ndecane droplets on the plates treated with CoBST and CeBST nanofluids are shown in Figs. 10(b) and 10(c). As can be seen from these figures, the superhydrophobicity of the coatings remains well after 20 cycles of abrasion, but their superamphiphobicity decline after about 16 cycles.

The resistance capability of the prepared nanofluids to high temperatures is very crucial in terms of industrial applications, such as wettability alteration of liquid wet rocks of gas condensate reservoirs to a superamphiphobic state by nanofluid stimulation. The degradation of nanofluids under high temperature is a major concern in this field. Hence, to meet the requirements of a high reservoir temperature, the thermal stability of the nanofluids was tested and verified. It should be noted that a large number of the gas-condensate reservoirs, where water and condensate blocking phenomenon are encountered, occurs at 130 to $150{ }^{\circ} \mathrm{C} .{ }^{30}$ Therefore, the effect of temperature on the superamphiphobicity of CoBST and CeBST nanotextures was studied by measuring the contact angles of water and n-decane droplets on surfaces treated with the nanofluids at different temperatures up to $180{ }^{\circ} \mathrm{C}$. The experimental procedure and results are explained here briefly. As previously stated, to treat the rock plates they were totally immersed into the nanofluids solution and aged in an oven at $80{ }^{\circ} \mathrm{C}$ for 24 hours (see Supporting Information, S1). In order to investigate the thermal stability, we prepared different plates with various annealing temperatures up to $180{ }^{\circ} \mathrm{C}$ and then the repellency of samples toward water and oil was studied by contact angle measurement. As shown in Fig. 11, the nanostructure coatings on the treated plates maintain well their superhydrophobicity and ultra oleophobicity at these elevated temperatures. 

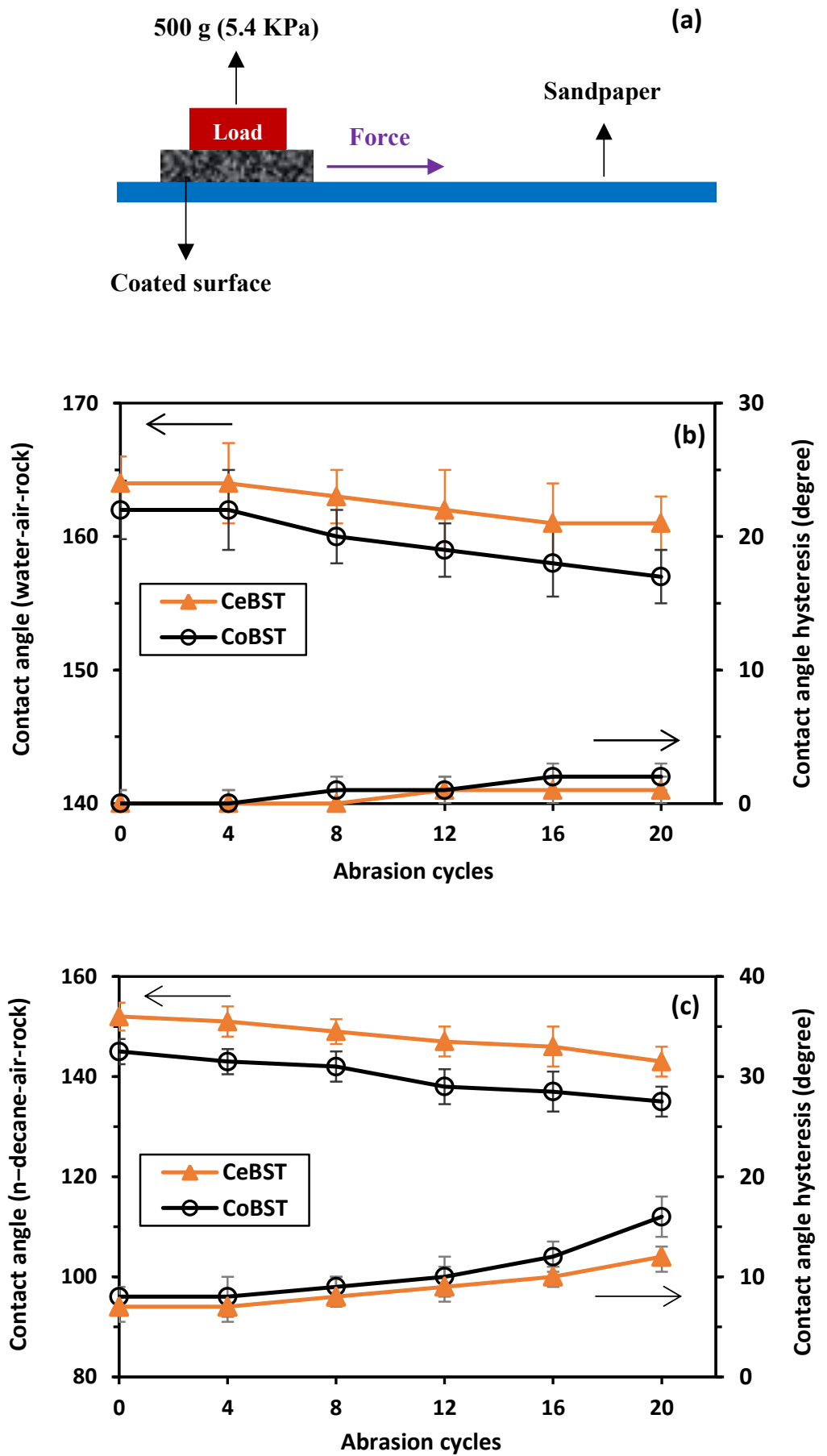

Fig. 10 (a) Schematic representation of abrasion test employed to evaluate the mechanical stability of the coatings. (b) water and (c) n-decane contact angle and contact angle hysteresis variations on the treated rock plates with CoBST and CeBST nanofluids as a function of abrasion cycles. 

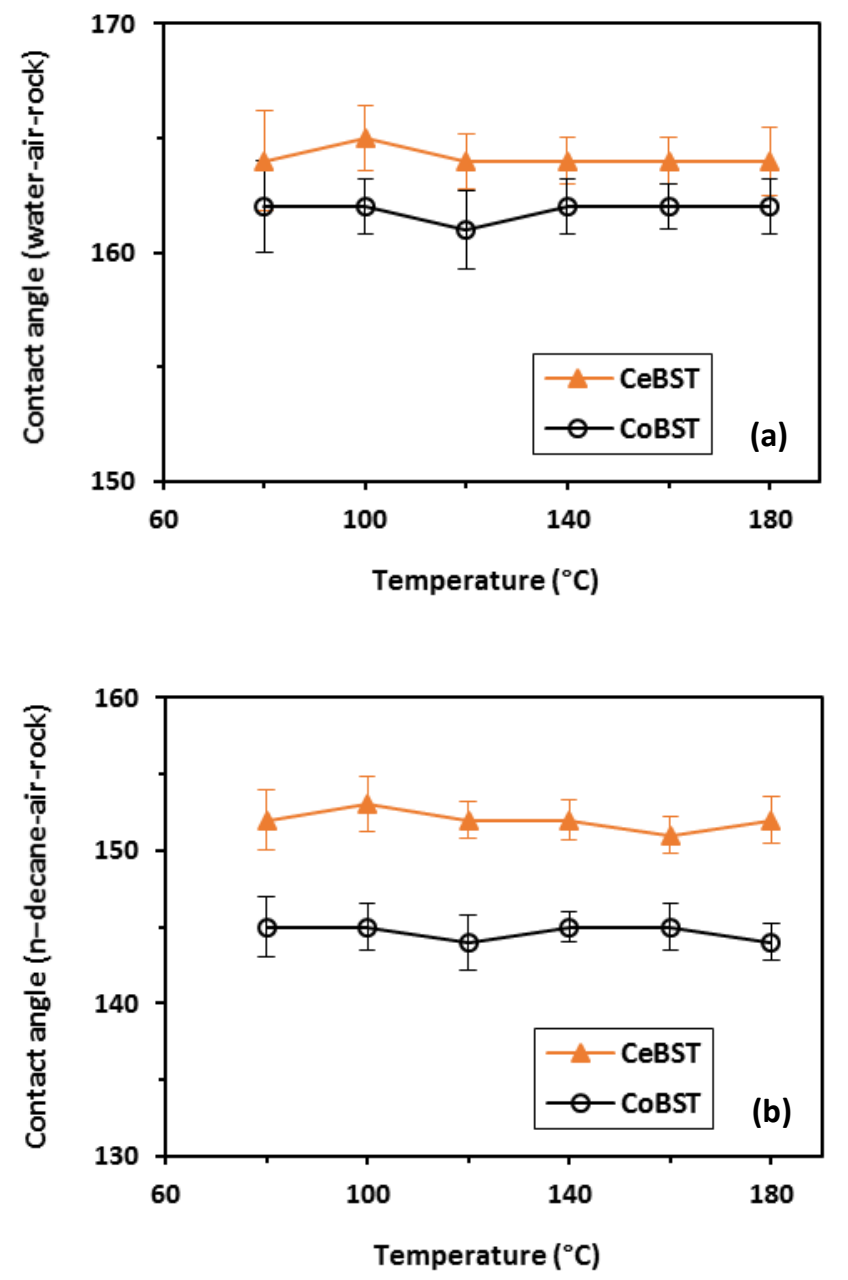

Fig. 11. Change in the (a) water and (b) n-decane contact angle of the treated rock plates with CoBST and CeBST nanofluids as a function of treatment temperature.

\section{Conclusions}

The novel superamphiphobic nanofluids, based on the synthesized CoBST and CeBST nanoparticles and fluorochemicals as PTFE and PFOS nanofluids, resulted in formation of rough nanostructure coatings on the solid surface, showing multi-functional properties such as super water and oil repellency toward various liquids ranging from 23 to $72.3 \mathrm{mN} / \mathrm{m}$, a sliding angle of $0^{\circ}$, self-cleaning properties, and good thermal stability. Surface characterization of the coated plates was carried out by SEM and EDX analyses. Accordingly, the superamphiphobicity is ascribed to the roughness of the nanoparticles that adsorb onto the microscale texture of a rock surface and the low surface energy of fluorochemicals. Based on our results, applying these multi-functional coatings on reservoir rock shows a promising practical application of the 
fabricated nanofluids for solving the problem of condensate blockage in gas condensate reservoirs, however, they can feasibly be employed for other means of rock treatment works as well.

\section{ASSOCIATED CONTENT}

\section{Supporting Information}

Note S1. Treatment process of rock plates with the nanofluids

Note S2. Instrumentation used.

Fig. S1. FTIR spectra of (a) CoBST and (b) CeBST powders over 4000-400 $\mathrm{cm}^{-1}$

Fig. S2. XRD patterns of cubic CoBST and CeBST nanostructures.

Fig. S3. UV-Vis absorption spectrum of synthesized CoBST and CeBST nanoparticles.

Fig. S4. EDX analysis of rock surface (a) before treatment and (b) and (c) after treatment with CoBST and CeBST nanofluids, respectively.

Fig. S5. Zisman plot for the rock surface treated with CoBST and CeBST nanofluids using nalkanes.

\section{Corresponding Authors}

E-mail: sadeghi@iust.ac.ir, abahram@ut.ac.ir and a.zarbakhsh@qmul.ac.uk

\section{References}

(1) Berendjchi, A.; Khajavi, R.; Yazdanshenas, ME. Fabrication of Superhydrophobic and Antibacterial Surface on Cotton Fabric by Doped Silica-Based Sols with Nanoparticles of Copper Nanoscale Res. Lett. 2011, 6, 594-602.

(2) Zhang, X.; Shi, F.; Niu, J.; Jiang, Y.; Wang, Z. Superhydrophobic Surfaces: From Structural Control to Functional Application J. Mater. Chem. 2008, 18, 621-633.

(3) Kim, E.; Kim, JY.; Kim, SS. Synthesis of Superhydrophobic SiO2 Layers via Combination of Surface Roughness and Fluorination J. Solid State Chem. 2013, 197, $23-28$.

(4) Kapridaki, C.; Maravelaki-Kalaitzaki, P. $\mathrm{TiO}_{2}-\mathrm{SiO}_{2}-\mathrm{PDMS}$ Nano-Composite Hydrophobic Coating with Self-Cleaning Properties for Marble Protection Prog. Org. Coat. 2013, 76, 400410. 
(5) Wang, S.; Shi, J.; Liu, C.; Xie, C.; Wang, C. Fabrication of a Superhydrophobic Surface on a Wood Substrate Appl. Surf. Sci. 2011, 257, 9362-9365.

(6) Valipour Motlagh, N.; Birjandi, FC.; Sargolzaeic, J. Super-non-Wettable Surfaces: A Review Colloids Surf., A 2014, 448, 93-106.

(7) Barthlott, W.; Neinhuis, W. Purity of the Sacred Lotus, or Escape from Contamination in Biological Surfaces Planta 1997, 202, 1-8.

(8) Gao, X.; Jiang, L. Biophysics: Water-Repellent Legs of Water Striders Nature 2004, 432: 36.

(9) Plawsky, J.; Kim, J.; Schubert, E. Engineered Nanoporous and Nanostructured Films Mater. Today 2009, 12, 63-45.

(10) Yan, YY.; Gao, N.; Barthlott, W. Mimicking Natural Superhydrophobic Surfaces and Grasping the Wetting Process: A Review on Recent Progress in Preparing Superhydrophobic Surfaces Adv. Colloid Interface Sci. 2011, 169, 80-105.

(11) Celia, E.; Darmanin, T.; Givenchy, ET.; Amigoni, S.; Guittard, F. Recent Advances in Designing Superhydrophobic Surfaces J. Colloid Interface Sci. 2013, 402, 1-18.

(12) Ma, M.; Hill, RM. Superhydrophobic Surfaces. Curr. Opin. Colloid Interface Sci. 2006, 11, 193-202.

(13) Nosonovsky, M.; Bhushan, B. Superhydrophobic Surfaces and Emerging Applications: Non-Adhesion, Energy, Green Engineering Curr. Opin. Colloid Interface Sci. 2009, 14, 270280 .

(14) Tuteja, A.; Choi, W.; Ma, M.; Mabry, J.; Mazzella, S.; Rutledge, G.; Mckinley, G.; Cohen, R. Designing Superoleophobic Surfaces Science 2007, 318, 1618-1622.

(15) Hsieh, CT.; Wu, FL.; Chen, WY. Superhydrophobicity and Superoleophobicity from Hierarchical Silica Sphere Stacking Layers Mater. Chem. Phys. 2010, 121, 14-21.

(16) Basu, B.; Kumar, VD.; Anandan, C. Surface Studies on Superhydrophobic and Oleophobic Polydimethylsiloxane-Silica Nanocomposite Coating System Appl. Surf. Sci. 2012, $261,807-814$.

(17) Steele, A.; Bayer, I.; Loth, E. Inherently Superoleophobic Nanocomposite Coatings by Spray Atomization Nano Lett. 2009, 9, 501-505.

(18) Barthwal, S.; Kim, Y.; Lim, SH. Fabrication of Amphiphobic Surface by using Titanium Anodization for Large-Area Three-Dimensional Substrates J. Colloid Interface Sci. 2013, 400, $123-129$. 
(19) Lu, Y.; Song, J.; Liu, X.; Xu, W.; Xing, Y.; Wei, Z. Preparation of Superoleophobic and Superhydrophobic Titanium Surfaces via an Environmentally Friendly Electrochemical Etching Method ACS Sustainable Chem. Eng. 2013, 1, 102-109.

(20) Hsieh, CT.; Chang, BS.; Lin, JY. Improvement of Water and Oil Repellency on Wood Substrates by using Fluorinated Silica Nanocoating Appl. Surf. Sci. 2011, 257, 7997-8002.

(21) Valipour Motlagh, N.; Birjandi, FC.; Sargolzaei, J.; Shahtahmassebi, N. Durable, Superhydrophobic, Superoleophobic and Corrosion Resistant Coating on the Stainless Steel Surface using a Scalable Method Appl. Surf. Sci. 2013, 283, 636-647.

(22) Yang, H.; Pi, P.; Cai, ZQ.; Wen, X.; Wang, X.; Cheng, J.; Yang, Z. Facile preparation of super-hydrophobic and super-oleophilic silica film on stainless steel mesh via sol-gel process Appl. Surf. Sci. 2010, 256, 4095-4102.

(23) Yao, X.; Gao, J.; Song, Y.; Jiang, L. Superoleophobic Surfaces with Controllable Oil Adhesion and Their Application in Oil Transportation Adv. Funct. Mater. 2011, 21, 4270-4276.

(24) Aminayi, P.; Abidi, N. Ultra-Oleophobic Cotton Fabric Prepared using Molecular and Nanoparticle Vapor Deposition Methods Surf. Coat. Technol. 2015, 276, 636-644.

(25) Manoudis, PN.; Tsakalof, A.; Karapanagiotis, I.; Zuburtikudis, I.; Panayiotou, C. Fabrication of Super-Hydrophobic Surfaces for Enhanced Stone Protection Surf. Coat. Technol. 2009, 203, 1322-1328.

(26) Li, K.; Firoozabadi, A. Phenomenological Modeling of Critical Condensate Saturation and Relative Permeabilities in Gas/Condensate Systems SPE J. 2000, 5, 138-147.

(27) Afidick, D.; Kaczorowski, NJ.; Bette, S. Production Performance of a Retrograde Gas Reservoir: A Case Study of the Arun Field SPE Asia Pac. Oil Gas Conf. Melbourne, Australia; 1994.

(28) Li, K.; Firoozabadi, A. Experimental Study of Wettability Alteration to Preferential GasWetting in Porous Media and its Effects SPE Reservoir Eval. Eng. 2000, 3, 139-149.

(29) Tang, GQ.; Firoozabadi, A. Relative Permeability Modification in Gas/Liquid Systems Through Wettability Alteration to Intermediate Gas Wetting SPE Reservoir Eval. Eng. 2002, 5, 427-436.

(30) Fahes, M.; Firoozabadi, A. Wettability Alteration to Intermediate Gas-Wetting in Gas Condensate Reservoirs at High Temperatures SPE J. 2007, 12, 397-407.

(31) Wu, S.; Firoozabadi, A. Permanent Alteration of Porous Media Wettability from LiquidWetting to Intermediate Gas-Wetting Transp. Porous Media 2010, 85, 189-213. 
(32) Xie, X.; Liu, Y.; Sharma, M.; Weiss, WW. Wettability Alteration to Increase Deliverability of Gas Production Wells J. Nat. Gas Sci. Eng. 2009, 1, 39-45.

(33) Feng, C.; Kong, Y.; Jiang, G.; Yang, J.; Pu, C.; Zhang, Y. Wettability Modification of Rock Cores by Fluorinated Copolymer Emulsion for the Enhancement of Gas and Oil Recovery Appl. Surf. Sci. 2012, 258, 7075-7081.

(34) Sharifzadeh, S.; Hassanajili, S.; Rahimpour, MR. Wettability Alteration of Gas Condensate Reservoir Rocks to Gas Wetness by Sol-Gel Process using Fluoroalkylsilane J. Appl. Polym. Sci. 2012, 128, 4077-4085.

(35) Wang, SF.; Wang, YR.; Wu, YC.; Liu, YJ. Densification, Microstructural Evolution, and Dielectric Properties of Hexagonal $\mathrm{Ba}\left(\mathrm{Ti}_{1-\mathrm{x}} \mathrm{Mn}_{\mathrm{x}}\right) \mathrm{O}_{3}$ Ceramics Sintered with Fluxes J. Alloys Compd. 2009, 480, 499-504.

(36) Cernea, M.; Andronescu, E.; Radu, R.; Fochi, F.; Galassi, C. Sol-Gel Synthesis and Characterization of BaTiO3-doped $\left(\mathrm{Bi}_{0.5} \mathrm{Na}_{0.5}\right) \mathrm{TiO}_{3}$ Piezoelectric Ceramics J. Alloys Compd. 2010, 490, 690-694.

(37) Guo, H.; Gao, W.; Yoo, J. The Effect of Sintering on the Properties of $\mathrm{Ba}_{0.7} \mathrm{Sr}_{0.3} \mathrm{TiO}_{3}$ Ferroelectric Films Produced by Electrophoretic Deposition Mater. Lett. 2004, 58, 1387-1391.

(38) Wu, D.; Zhu, H.; Wang, L.; Liu, L. Critical Issues in Nanofluids Preparation, Characterization and Thermal Conductivity Curr. Nanosci. 2009, 5, 103-112.

(39) Hwang, Y.; Lee, J.; Jeong, Y.; Cheong, S.; Ahn, Y.; Kim, S. Production and Dispersion Stability of Nanoparticles in Nanofluids Powder Technol. 2008, 186, 145-153.

(40) Ries, A.; Simões, A.; Cilense, M.; Zaghete, M.; Varela, J. Barium Strontium Titanate Powder Obtained by Polymeric Precursor Method Mater. Charact. 2003, 50, 217-221.

(41) Ioachim, A.; Toacsan, M.; Banciu, M.; Nedelcu, L.; Vasiliu, F.; Alexandru, H.; Berbecaru, C.; Stoica, G. Barium Strontium Titanate-Based Perovskite Materials for Microwave Applications Prog. Solid State Chem. 2007, 35, 513-520.

(42) Simões, A.; Moura, F.; Onofre, T.; Ramirez, M.; Varela, J.; Longo, E. MicrowaveHydrothermal Synthesis of Barium Strontium Titanate Nanoparticles J. Alloys Compd. 2010, $508,620-624$.

(43) Tsay, JD.; Fang, TT.; Gubiotti, TA.; Ying, JY. Evolution of the Formation of Barium Titanate in the Citrate Process: The Effect of the $\mathrm{pH}$ and the Molar Ratio of Barium Ion and Citric Acid J. Mater. Sci. 1998, 33, 3721-3727.

(44) Mohamed, SH.; Dughaish, ZH. Microstructural and Optical Investigations of Ce-Doped Barium Titanate Thin Films by FTIR and Spectroscopic Ellipsometry Philos. Mag. 2012, 92, 1212-1222. 
(45) Khollam, Y.; Potdar, H.; Deshpande, S.; Gaikwad, A. Synthesis of Star Shaped Ba ${ }_{x} \mathrm{Sr}_{\mathrm{x}} \mathrm{TiO}_{3}$ (BST) Powders Mater. Chem. Phys. 2006, 97, 295-300.

(46) Fakhroueian, Z.; Farzaneh, F.; Afrookhteh, N. Oxidative Coupling of Methane Catalyzed by Li, Na and Mg Doped BaSrTiO3 Fuel 2008, 87, 2512-2516.

(47) Badr, MH.; Sharaf El-Deen, LM.; Khafgy, AH. Structural and Mechanical Properties Characterization of Barium Strontium Titanate (BST) Ceramics J. Electroceram. 2011, 27, 189196.

(48) Zhang, S.; Jiang, GC.; Wang, L.; Qing, W.; Guo, HT.; Tang, X.; Bal, DG. Wettability alteration to Intermediate Gas-Wetting in Low-Permeability Gas-Condensate Reservoirs J. Pet. Explor. Prod. Technol. 2014, 4, 301-308.

(49) Cassie, ABD.; Baxter, S. Wettability of Porous Surfaces Trans. Faraday Soc. 1994, 40, $546-551$.

(50) Shibuichi, S.; Yamamoto, T.; Onda, T.; Tsujii, K. Super Water- and Oil-Repellent Surfaces Resulting from Fractal Structure J. Colloid Interface Sci. 1998, 208, 287-294.

(51) Xie, Q.; Xu, J.; Feng, L.; Jiang, L.; Tang, W.; Luo, X.; Han, C. Facile Creation of a Super-Amphiphobic Coating Surface with Bionic Microstructure Adv. Mater. 2004, 16, 302305.

(52) Muthiah, P.; Bhushan, B.; Yun, K.; Kondo, H. Dual-Layered-Coated MechanicallyDurable Superomniphobic Surfaces with Anti-Smudge Properties J. Colloid Interface Sci. 2013, 409, 227-236.

(53) Ogihara, H.; Xie, J.; Okagaki, J.; Saji, T. Simple Method for Preparing Superhydrophobic Paper: Spray-Deposited Hydrophobic Silica Nanoparticle Coatings Exhibit High WaterRepellency and Transparency Langmuir 2012, 28, 4605-4608.

(54) Ma, J.; Zhang, X.; Wang, D.; Zhao, D.; Ding, D.; Liu, K.; Wang, W. Superhydrophobic Metallic Glass Surface with Superior Mechanical Stability and Corrosion Resistance Appl. Phys. Lett. 2014, 104, 173701-173704.

(55) Tang, M.; Huang, X.; Li, X.; Huang, Z.; Zhang, S.; Zhang, Q. Fabrication of Superhydrophobic Surface with Superior Anticorrosion and Great Mechanical Stability on AA7075 Al Alloy via a Convenient and Efficient Approach Mater. Express 2016, 6, 101-115. 
Table of Contents Graphic

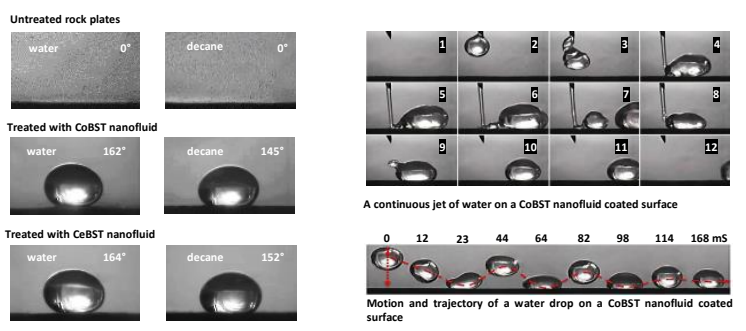

